\title{
ESSENCE AND TYPES OF FUNCTIONS OF CIVIL LAW
}

\author{
Oleg V. Zaytsev \\ Russian Presidential Academy of National Economy and Public Administration, \\ Moscow, Russian Federation
}

\begin{abstract}
Annotation. Introduction. Understanding the system of civil law regulation is impossible without assessing the role and significance of such legal phenomenon as the functions of civil law. The purpose of this article was to consider the essence and types of functions of civil law in conjunction with the doctrine of civil law. The author examines the system of civil law regulation taking into account the assessment of the role and significance of such legal phenomenon as the functions of civil law. With the help of methods of scientific cognition, first of all, the method of system analysis, it is established that the functions of law determine the direction of development of the content of the law. The peculiarity of the functions of civil law is associated with the specifics of both the subject and the method of civil law regulation. As a result of the research, the author comes to the conclusion that the functions of civil law are determined by the doctrine, and the external manifestation of this legal influence by the guiding principles of civil law for all participants of the legal process.

Key words: civil law, civil law functions, principles of civil law, civil legal relationship.
\end{abstract}

УДК 342.3

ББК 67.011

\section{СУЩНОСТЬ И ВИДЫ ФУНКЦИЙ ГРАЖДАНСКОГО ПРАВА}

\author{
Олег Владимирович Зайцев \\ Российская академия народного хозяйства и государственной службы при Президенте РФ, \\ г. Москва, Российская Федерация
}

Введение. Понимание системы гражданско-правового регулирования невозможно без оценки роли и значимости такого юридического феномена как функции гражданского права. Целью написания данной статьи стало рассмотрение сущности и видов функций гражданского права во взаимосвязи с доктриной гражданского права. Для этого автор исследует систему гражданско-правового регулирования с учетом оценки роли и значимости такого юридического феномена, как функции гражданского права. С помощью методов научного познания, прежде всего, метода системного анализа, установлено, что именно функции права определяют направление развития содержания норм права. Особенность функций гражданского права связана со спецификой как предмета, так и метода гражданско-правового регулирования. В результате исследования автор приходит к выводу, что функции гражданского права определяются доктриной, а внешним проявлением этого правового воздействия, ориентиром для всех участников правоприменительного процесса выступают принципы гражданского права.

Ключевые слова: гражданское право, функции гражданского права, принципы гражданского права, гражданское правоотношение.

\section{Введение}

Понимание системы гражданско-правового регулирования невозможно без оценки роли и значимости такого юридического феномена как функции гражданского права, «в которых раскрывается его социальное назначение (востребованность обществом). Реализация функций характеризует внешнее проявление права» [6, с. 13]. Они определяют основное направление и характер юридических средств воздействия той или иной отрас- 
ли права на общественные отношения. В литературе высказывается мнение, что в вопросе о функциях гражданского права (понятии, видах, содержании, соотношении с иными правовыми конструкциями и т. д.) единство взглядов отсутствует [7, с. 57]. Однако хотелось бы выразить несогласие с данным утверждением. Как показывает анализ юридической литературы, серьезных разногласий по данным вопросам не наблюдается.

\section{Основные функции гражданского права}

В большей степени вся дискуссия относительно функций права протекает в сфере теоретических исследований, чем в отраслевых научных работах, связанных с гражданским правом. Те или иные мнения и позиции, относительно функций гражданского права, высказываются в связи с изучением иных предметных вопросов гражданского права.Так, например, отмечается, что в теории права презюмируется общее понимание функции права как направления правового воздействия на общественные отношения. При этом указывается, что нельзя не отметить воздействия права не только на общественные отношения, но и на сознание, волю и действия людей, что характеризует воспитательную функцию права $[1$, с. 80$]$. Однако многие авторы выделяют и превентивную функцию права, что также имеет непосредственное воздействие на сознание людей и опосредованное на общественные отношения. Четко разграничить данное воздействие вряд ли возможно, в связи с чем и само разделение указанных выше функций достаточно затруднительно и в большей степени зависит от позиции того или иного исследователя.

К основным функциям в гражданском праве относятся регулятивная, охранительная, правозащитная, воспитательная, компенсационная, восстановительная. Данный перечень не является исчерпывающим и может дополняться функциями, имеющими межотраслевой характер. А.Я. Рыженков, например, наиболее значимой классификацией функций права считает их деление в зависимости от способа воздействия и сферы реализации норм права. При таком подходе выделяются юридические функции (регулятивная и охранитель- ная), социальная (экономическая, политическая, социальная и пр.).

Особый характер имеет воспитательная функция. Также автор считает необходимым в особый вид выделить правозащитную функцию, не отождествляя ее с охранительной [15]. Н. Боббио, профессор Туринского университета, выделяет понятие «поощрительной функции права», правда, считая этот термин не совсем удачным [2, с. 128]. Поощрительная функция - действие, которое оказывает право, когда используются позитивные санкции, то есть те побудительные механизмы, которые содержит в себе та или иная отрасль права, направленные на стимулирование общественно полезных действий [2, с. 128]. По нашему мнению, четкого выражения в гражданском праве данная функция не имеет, хотя отдельные проявления механизма стимулирования общественно полезных действий, несомненно, присутствуют. Но в большей степени они проявляются за счет действия неких ограничительных правовых средств, когда действия одного из участников гражданских правоотношений ограничиваются общественными или публичными интересами. Так, например, К. Бевилаква воспринимает социальную функцию права собственности как правовой принцип для того, чтобы оправдать внешние ограничения права собственности $[8$, c. 38$]$.

\section{Воздействие функций права на гражданские правоотношения}

Нам представляется важным не столько выявление конкретных функций гражданского права, сколько определение роли данного правового феномена и его взаимодействие с иными регуляторами, оказывающими воздействие на гражданско-правовые отношения. Совершенно верно отмечено, что «специфику функций гражданского права следует искать в особенностях предмета правового регулирования гражданского права» [15, с. 44]. В функциях права находит отражение его предмет, то есть вся сфера отношений, подпадающая под действие права [11, с. 652].

Хотелось бы еще добавить, что помимо предмета, особенность функций гражданского права связана и со спецификой метода 
гражданско-правового регулирования. Взаимообусловленность предмета, метода правового регулирования и функций права связана с тем воздействием способа регулирования, определяющего ту или иную отрасль права, на отношения, вовлекаемые под воздействием экономических, социальных или политических преобразований в соответствующий предмет правового регулирования. Наиболее ярким примером является включение в предмет гражданского права корпоративных отношений.

Несомненно, что расширение предмета гражданско-правового регулирования повлекло и изменения в самих регулируемых общественных отношениях, прежде всего, под влиянием метода гражданского права, что, в частности, проявляется в презумпции свободы договора в корпоративных отношениях. В литературе верно отмечается, что необходимо выбирать надлежащий метод и способы правового регулирования, учитывая взаимодействие регулятивной функции права с другими видами социального регулирования, включая корпоративное, политическое и моральное, выявлять роль и значение правосознания [5, c. 14]. Корпоративное право демонстрирует нам подобное взаимодействие. Достаточно значительное локальное регулирование, проявляющееся в сфере корпоративного управления в виде актов рекомендательного характера, своим следствием получило закрепление в п. 5 ст. 52 ГК РФ, в соответствии с которым признается, что учредители (участники) юридического лица вправе утвердить регулирующие корпоративные отношения и не являющиеся учредительными документами внутренний регламент и иные внутренние документы юридического лица. Рассматриваемые изменения связаны с наличием кооперационно-координирующей функции гражданского права [14].

\section{Характеристика функций права}

Итак, главным в характеристике функций права является определение правового воздействия на общественные отношения путем выявления роли (назначения) права в обществе в целом [1]. Для такой отрасли как гражданское право это общетеоретическое утверждение имеет значимый смысл, так как без выявления роли частноправового регулирования в обществе невозможно выявить функции гражданского права. Как отмечал В.Ф. Яковлев, «правовой способ воздействия на общественные отношения отличается от всякого иного: а) четкостью нормативно-правовых предписаний, носящих характер прав и обязанностей участников регулируемых отношений; б) общеобязательностью этих предписаний, поскольку они представляют собой волю господствующего класса, возведенную в закон, то есть установленную или санкционированную государством; в) тем, что нормы права действуют не каждая в отдельности, а в совокупности с другими нормами как составная часть целой правовой системы» $[16$, c. 10]. Несмотря на кардинальные изменения в обществе и законодательстве, которые произошли с момента высказывания цитируемой идеи ученого, ее ценность и содержательное значение не изменились. А.Я. Рыженков, давая определение функции российского гражданского права, также отмечает, что это «обусловленное товарно-денежной формой и задачами российского государства воздействие гражданско-правовых норм на имущественные отношения, на связанные или не связанные с ними личные неимущественные отношения, в определенных и различных по сфере направлениях» [15, с. 45]. Конечно, следуя современным идеологическим установкам мы не можем говорить о наличии воли, господствующего класса, возведенной в закон, но наличие задач государства, которые проявляются в том числе и в функциях гражданского права, является общепризнаваемым. Профессор В.Ф. Яковлев писал, что «функция права в целом состоит в том, что оно служит государственно-классовым регулятором общественных отношений; но применительно к отдельным видам отношений, функция конкретизируется с учетом их характера» $[16$, с. 16]. Современные авторы также отмечают, что «содержание позитивного права, обработанного доктриной, носит формально-логически организованный характер и базируется на общих и отраслевых принципах права, которые рассматриваются как начала, пронизывающие все институты отрасли или системы права в целом» $[9$, с. 198]. Мы не можем не призна- 
вать роль позитивного права в определении той роли, которая отводится гражданскому праву в регулировании общественных отношений. И если функции определяются доктриной, то внешним проявлением этого правового воздействия и ориентиром для всех участников правоприменительного процесса выступают принципы гражданского права, как основное связующее звено между доктриной и законом.

Связь между рассматриваемыми правовыми элементами была подчеркнута В.Ф. Яковлевым: «Принципы как ведущие начала в праве отражают его классовую сущность ... Отраслевые принципы находят свое выражение в содержании прав и обязанностей данной отрасли права» [16, с. 16]. «Если принципы фокусируют в себе классовую сущность отрасли, функции - ее социальное назначение, то метод отражает содержание отрасли права под углом зрения способа воздействия данной отрасли на регулируемые отношения» [16, с. 16]. Также и С.А. Муромцев писал в свое время, что «юридический принцип указывает на то, что должно быть; закон на то, что есть в силу свойств человека, общества и мира» $[10$, с. 30]. В настоящее время, напротив, именно функции права определяют направления развития содержания норм права. Например, К. Карст рассматривает социальную функцию права с точки зрения ценностных ориентаций ... право создает институциональную основу для «согласования интересов» и путем установления норм обеспечивает защиту социальных ценностей [4, с. 302].

Важно отметить, что довольно часто в научной литературе отождествляются такие понятия как функция и метод правового регулирования, что недопустимо с методологической точки зрения [12, с. 23]. Под гражданскоправовыми функциями В.А. Рыбаковым понимается «обусловленное товарно-денежной формой и задачами государства воздействие гражданско-правовых норм на имущественные отношения и связанные с ними личные неимущественные отношения в определенных направлениях» [13; 14]. По мнению Е.В. Вавилина, именно «метод влияет на особенности, содержание и характер реализации функций гражданско-правового регулирования, а также позволяет наиболее полно раскрыть механизм обеспечения надлежащего осуществления права и исполнения обязанностей субъектами гражданского права» [3].

\section{Выводы}

Подводя итоги вышеизложенному, можно отметить, что функции гражданского права определяют направления развития содержания соответствующих норм права. При этом их особенность связана со спецификой как предмета, так и метода гражданско-правового регулирования, а что подчеркивает значимость определения роли данного правового феномена и его взаимодействия с иными регуляторами, оказывающими воздействие на гражданско-правовые отношения.

Функции гражданского права определяются доктриной, а внешним проявлением этого правового воздействия и ориентиром для всех участников правоприменительного процесса выступают принципы гражданского права, как основное связующее звено между доктриной и законом.

\section{СПИСОК ЛИТЕРАТУРЫ}

1. Абрамов, А. И. Понятие функции права / А. И. Абрамов // Журнал российского права. 2006. - № 2. - С. 71-83.

2. Боббио, Н. От структуры к функции. Новые исследования в теории права / Н. Боббио // Право XX века: идеи и ценности : сб. обзоров и рефератов ; отв. ред. Ю. С. Пивоваров. - М. : ИНИОНРАН, 2001. С. $128-138$.

3. Вавилин, Е. В. Механизм осуществления гражданских прав и исполнения обязанностей / Е. В. Вавилин. - М., 2009. -428 c.

4. Исаев, И. А. Право и общество (социолого-правовые проблемы в современной западной науке) / И. А. Исаев // Право ХХ века: идеи и ценности : сб. обзоров и рефератов ; отв. ред. Ю. С. Пивоваров. - М. : ИНИОН РАН, 2001. - 327 с.

5. Ковтун, 3. Л. Некоторые проблемы осуществления регулятивной функции права в современной России / 3. Л. Ковтун // Юридический вестник Кубанского государственного университета. - 2013. № 1. - С. 12-15.

6. Куксин, И. Н. Теоретические основы классификации функций права / И. Н. Куксин, П. А. Матвеев // Юридическая наука. - 2012. № 4. - C. 13-18. 
7. Ламм, Т. В. Реализация охранительной функции в гражданском праве / Т. В. Ламм // Защита частных прав: проблемы теории и практики : материалы междунар. науч.-практ. конф. / отв. ред. Н. П. Асланян. - Иркутск : Изд-во Байкальского государственного университета экономики и права, 2012. - С. 56-63.

8. Медведев, С. Н. Социальная функция права собственности в бразильском праве / С. Н. Медведев // Северо-Кавказский юридический вестник. 2013. - № 13. - С. 38-41.

9. Михайлов, А. М. Генезис континентальной юридической догматики / А. М. Михайлов. - М. : Юрлитинформ, 2012. - 496 с.

10. Муромцев, С. А. Определение и основное разделение права / С. А. Муромцев. - СПб. : Издат. Дом С.-Петерб. гос. ун-та, 2004. - 224 с.

11. Сидорова, Е. В. Генезис и динамика права как явления культуры / Е. В. Сидорова // Концепция философии права / под ред. В. П. Малахова. М. : Юнити-Дана, 2007. - С. 643-653.

12. Рыбаков, В. А. О методологических подходах к понятию функции права / В. А. Рыбаков, В. Н. Соловьев // Гражданское право. - 2012. № 1. - C. 19-23.

13. Рыбаков, В. А. О механизме реализации воспитательной функции гражданско-правового регулирования / В. А. Рыбаков // Гражданское право. 2009. - № 2. - С. 8-13.

14. Рыбаков, В. А. О функциях гражданско-правового регулирования / В. А. Рыбаков // Гражданское право. - 2009. - № 1. - Доступ из справ.-правовой системы «КонсультантПлюс». Версия: Проф.

15. Рыженков, А. Я. Функции гражданского права: вопросы теории / А. Я. Рыженков // Пробелы в российском законодательстве. Юридический журнал. - 2012. - № 4. - С. 44-49.

16. Яковлев, В. Ф. Гражданско-правовой метод регулирования общественных отношений / В. Ф. Яковлев. - Свердловск, 1972. -210 с.

\section{REFERENCES}

1. Abramov A.I. Ponyatie funktsii prava [The Concept of the Function of Law]. Zhurnal rossiyskogo prava, 2006, no. 2, pp. 71-83.

2. Bobbio N. Ot struktury k funktsii. Novye issledovaniya $\mathrm{v}$ teorii prava [From Structure to Function. New Research in the Theory of Law]. Pivovarov Yu.S., ed. Pravo XX veka: idei i tsennosti: sb. obzorov $i$ referatov [The Law of the $20^{\text {th }}$ Century: Ideas and Values: Collected Reviews and Abstracts]. Moscow, INION RAN Publ., 2001, pp. 128-138.
3. Vavilin E.V. Mekhanizm osushchestvleniya grazhdanskikh prav i ispolneniya obyazannostey [The Mechanism of Exercising Civil Rights and Duties]. Moscow, 2009. 428 p.

4. Isaev I.A. Pravo i obshchestvo (sotsiologopravovye problemy v sovremennoy zapadnoy nauke) [Law and Society (Socio-Legal Problems in Contemporary Western Science)]. Pivovarov Yu.S., ed. Pravo XX veka: idei i tsennosti: sb. obzorov i referatov [The Law of the $20^{\text {th }}$ Century: Ideas and Values: Collected Reviews and Abstracts]. Moscow, INION RAN Publ., 2001. 327 p.

5. Kovtun Z.L. Nekotorye problemy osushchestvleniya regulyativnoy funktsii prava $\mathrm{V}$ sovremennoy Rossii [Some Problems of the Implementation of the Regulatory Function of Law in Modern Russia]. Yuridicheskiy vestnik Kubanskogo gosudarstvennogo universiteta, 2013, no. 1, pp. 12-15.

6. Kuksin I.N., Matveev P.A. Teoreticheskie osnovy klassifikatsii funktsiy prava [The Theoretical Bases of Classification of Law Functions]. Yuridicheskaya nauka, 2012, no. 4, pp. 13-18.

7. Lamm T.V. Realizatsiya okhranitelnoy funktsii v grazhdanskom prave [Implementation of Protective Function in the Civil Law]. Aslanyan N.P., ed. Zashchita chastnykh prav: problemy teorii i praktiki: materialy mezhdunar. nauch.-prakt. konf. [Protection of Private Rights: Problems of Theory and Practice: Materials of the International Research and Practice Conference]. Irkutsk, Izd-vo Baykalskogo gos. un-ta ekonomiki i prava, 2012, pp. 56-63.

8. Medvedev S.N. Sotsialnaya funktsiya prava sobstvennosti v brazilskom prave [The Social Function of Property Rights in the Brazilian Law]. Severo-Kavkazskiy yuridicheskiy vestnik, 2013, no. 13 , pp. 38-41.

9. Mikhaylov A.M. Genezis kontinentalnoy yuridicheskoy dogmatiki [The Genesis of Continental Legal Dogmatics]. Moscow, Yurlitinform Publ., 2012. $496 \mathrm{p}$.

10. Muromtsev S.A. Opredelenie i osnovnoe razdelenie prava [The Definition and the Basic Division of Law]. Saint Petersburg, Izdat. Dom S.-Peterb. gos. un-ta, 2004. 224 p.

11. Sidorova E.V. Genezis i dinamika prava kak yavleniya kultury [The Genesis and Dynamics of Law as a Cultural Phenomenon]. Malakhov V.P., ed. Kontseptsiya filosofii prava [The Conception of the Philosophy of Law. Academic Schools of the Moscow University of the Ministry of the Interior of Russia]. Moscow, Yuniti-Dana Publ., 2007, pp. 643-653.

12. Rybakov V.A., Solovyev V.N. O metodologicheskikh podkhodakh k ponyatiyu funktsii prava [On the Methodological Approaches to the Concept 
of the Function of Law]. Grazhdanskoe pravo, 2012, no. 1, pp. 19-23.

13. Rybakov V.A. O mekhanizme realizatsii vospitatelnoy funktsii grazhdansko-pravovogo regu lirovaniya [On the Mechanism for Implementing the Educational Function of Civil-Law Regulation]. Grazhdanskoe pravo, 2009, no. 2, pp. 8-13.

14. Rybakov V.A. O funktsiyakh grazhdanskopravovogo regulirovaniya [On the Functions of CivilLaw Regulation]. Grazhdanskoe pravo, 2009, no. 1.
Access from Reference Legal System "Konsultant Plyus".

15. Ryzhenkov A.Ya. Funktsii grazhdanskogo prava: voprosy teorii [Civil Law Functions: Theory Issues]. Probely $v$ rossiyskom zakonodatelstve. Yuridicheskiy zhurnal, 2012, no. 4, pp. 44-49.

16. Yakovlev V.F. Grazhdansko-pravovoy metod regulirovaniya obshchestvennykh otnosheniy [The Civil-Law Method of Regulating Public Relations]. Sverdlovsk, 1972. 210 p.

\section{Information about the Author}

Oleg V. Zaytsev, Candidate of Juridical Sciences, Associate Professor, Head of Supreme School of Law, Institute of Public Administration and Management, Russian Presidential Academy of National Economy and Public Administration, Prosp. Vernadskogo, 82, bld. 1, 119571 Moscow, Russian Federation, ov.zaytsev@migsu.ru.

\section{Информация об авторе}

Олег Владимирович Зайцев, кандидат юридических наук, доцент, заведующий Высшей школой правоведения института государственной службы и управления, Российская академия народного хозяйства и государственной службы при Президенте РФ, просп. Вернадского, 82, стр. 1, 119571 г. Москва, Российская Федерация, ov.zaytsev@migsu.ru. 